\title{
Human hepatocyte growth factor levels in patients undergoing thoracic operations
}

\author{
E. Dikmen*, M. Kara*, U. Kisa\#, C. Atinkaya*, S. Han` and U. Sakinci"
}

\begin{abstract}
Human hepatocyte growth factor (hHGF) is the most potent mitogen identified for alveolar type II cells, and may have other important functions in the repair of the alveolar epithelium and compensatory lung growth. A study was conducted to evaluate the changes of serum hHGF levels in patients who underwent thoracic surgical procedures.

The patients comprised 17 males and 14 females with a mean age of $47.1 \pm 13.5$ yrs, who underwent either lung resection (LR group) or nonlung resection (nonLR group) thoracic procedures. The changes of hHGF levels were analysed in the pre- and post-operative periods in both groups.

The pre-operative hHGF levels did not differ between the LR and the nonLR groups, which were $333.2 \pm 72.9 \mathrm{pg} \cdot \mathrm{mL}^{-1}$ and $343.6 \pm 125.3 \mathrm{pg} \cdot \mathrm{mL}^{-1}$, respectively. The hHGF levels in the LR group significantly increased up to $433.6 \pm 128.1 \mathrm{pg} \cdot \mathrm{mL}^{-1}$ and $430.8 \pm 128.2 \mathrm{pg} \cdot \mathrm{mL}^{-1}$ in post-operative days 1 and 3 , respectively. However, the same levels in the nonLR group appeared as $333.2 \pm 77.0 \mathrm{pg} \cdot \mathrm{mL}^{-1}$ and $311.9 \pm 73.0 \mathrm{pg} \cdot \mathrm{mL}^{-1}$, respectively.

In conclusion, the increases of serum human hepatocyte growth factor levels following pulmonary resection may imply the important role of human hepatocyte growth factor in lung regeneration or compensatory lung growth in humans.
\end{abstract}

\section{KEYWORDS: Hepatocyte growth factor, pulmonary resection, surgery}

D ost-operative respiratory failure and potential residual space problems are major clinical concerns following pulmonary resection in thoracic surgery. Persistent pleural air spaces following lobectomy or lesser resections are common and may be inevitably infected unless treated. The mechanisms involved in the regulation and obliteration of the residual space are: mediastinal shift toward the operated side; elevation of the ipsilateral diaphragmatic leaf; narrowing of the intercostal spaces with internal bulging of the intercostal muscles; intrapleural accumulation of blood with serum in the pleural cavity; and compensatory growth of the remaining lung $[1,2]$. Among these mechanisms, compensatory growth of the remaining lung is of particular significance as well as the compliance of the lung, which can also be qualitatively assessed intra-operatively. In addition to these physiological mechanisms, numerous intra-operative and post-operative prophylactic measures, such as tailoring thoracoplasty, pleural tent, pneumoperitoneum, phrenic crush and post-operative high intrapleural suction, have been suggested to overcome the postoperative space problems [2].

Over-distension, emphysematous changes, hyperplasia with fragmentation of alveoli and loss of following pulmonary resection, which all subsequently result in compensatory growth of the lung [1, 3-7]. Proliferation of alveolar type II cells is thought to be critical for the restoration of lung function after diffuse alveolar damage or major lung resections. Numerous growth factors including epidermal growth factor, insulin-like growth factor-I, keratinocyte growth factor, retinoic acid and hepatocyte growth factor (HGF) have been shown to take part in the process of compensatory growth of the lung [3-6]. Among these factors, HGF and keratinocyte growth factor appear to be the principal mitogens for alveolar type II cells, and contribute to alveolar epithelial repair following lung injury [5].

HGF was originally characterised as a potent mitogen for hepatocytes. It is a multifunctional growth factor for epithelial and microvascular endothelial cells, a mitogen that causes epithelial cells to lose focal adhesions and scatter, and a morphogen that stimulates the formation of tubular structures of certain epithelial cells [7]. Previous data have shown that HGF also had a pulmotrophic effect, which might have an effect on compensatory growth following pulmonary resection [8]. elastic tissue occur in the remaining lung
AFFILIATIONS

Depts of *Thoracic Surgery, and

${ }^{*}$ Biochemistry, University of

Kirikkale, School of Medicine,

Kirikkale, and

'Dept of Thoracic Surgery, Numune Education and Research Hospital,

Ankara, Turkey

CORRESPONDENCE

E. Dikmen

Bulbulderesi caddesi 65/8

TR-06660

Kucukesat

Ankara

Turkey

Fax: 903182252819

E-mail: dikmenerkan@hotmail.com

Received:

December 282004

Accepted after revision:

August 062005

SUPPORT STATEMENT

This study was supported by a grant from the Research Foundation of University of Kirikkale, Turkey (project-Nr 02/08-03-07). 
Although numerous reports have appeared regarding the pulmotrophic effect of HGF in animal models [8,9], the current authors are aware of few reports regarding the changes of human hepatocyte growth factor (hHGF) levels following pulmonary resections in humans [6, 10]. A study was conducted to examine the changes of serum hHGF levels in patients who underwent thoracic surgical procedures. hHGF levels were measured in patients who underwent lung resection (LR) thoracic procedures and the results compared against patients who underwent nonlung resection (nonLR) thoracic procedures.

\section{METHODS}

\section{Patients and samples}

Serum samples were collected from a total of 31 patients who underwent thoracic operations in Kirikkale University Hospital and Numune Education and Research Hospital (both Turkey). Samples were obtained in the pre-operative period and at post-operative days (POD) 1,3 , and 14. In total there were 17 males and 14 females with a mean age of $47.1 \pm 13.5$ yrs (range 16-72). Patients were classified into two groups as follows: 1) LR group, which consisted of 18 patients who underwent LR procedures such as wedge resection, lobectomy or pneumonectomy; and 2) nonLR group, which consisted of 13 patients who underwent thoracic operations apart from LR.

The patients in the LR group were 11 males and seven females, with a mean age of $50.2 \pm 12.8$ yrs (range $31-72$ ). Lobectomy was the most common procedure in $14(77.7 \%)$ patients followed by wedge resection in three $(16.7 \%)$ patients and pneumonectomy in one $(5.6 \%)$ patient. Definitive diagnosis was bronchogenic carcinoma in 10 (55.5\%) patients, bronchiectasis in five $(27.8 \%)$ patients and interstitial lung diseases in three $(16.7 \%)$ patients. Among the bronchogenic carcinoma cases, histological diagnosis was squamous cell carcinoma in six cases and adenocarcinoma in four cases.

The nonLR group comprised of seven females and six males with a mean age of $43.0 \pm 13.7$ yrs (range 16-66). The surgical procedures in the nonLR group were: videothoracoscopic pleural biopsy $(n=3)$; chest wall resection $(n=2)$; enucleation of pulmonary hamartoma $(n=2)$; transaxillary first and cervical ribs resection $(n=2)$; thymectomy $(n=1)$; posterior mediastinal mass excision $(n=1)$; cystotomy+capitonnage for a pulmonary hydatid cyst $(n=1)$; and a thoracal sympathectomy for upper limp hyperhidrosis $(n=1)$.

A total of 13 healthy subjects with normal biochemical functions served as controls. Patients with either hepatic dysfunction resulting from hepatitis or renal dysfunction were not included. Informed consent was obtained from each patient or other responsible individuals.

\section{Measurement of hHGF}

Serum samples were separated by centrifugation of the blood at $1,500 \times g$ for $10 \mathrm{~min}$ and stored at $-70^{\circ} \mathrm{C}$ until measured by hHGF. Serum hHGF levels were measured using a solid phase sandwich ELISA (Human HGF Immunoassay Kit; Biosource International Inc., Camarillo, CA, USA). The calibration curve was prepared with hHGF standards of $0,156,312,625,1,250$ and $2,500 \mathrm{pg} \cdot \mathrm{mL}^{-1}$. The results were given as $\mathrm{pg} \cdot \mathrm{mL}^{-1}$.

\section{Statistical analysis}

Patients were also stratified as malignant and benign groups with respect to the histological and operative diagnosis for statistical comparisons. Pre-operative and POD 1, 3 and 14 values were compared either between the groups or in the groups. Results were analysed with the ANOVA test, student's t-test and paired t-tests as appropriate for comparison of mean values. Data were expressed as mean \pm SD. A p-value $<0.05$ was considered as statistically significant.

\section{RESULTS}

The pre-operative hHGF levels did not differ between the groups $(p=0.879)$. The pre-operative hHGF levels in the LR group and the nonLR group were $333.2 \pm 72.9 \mathrm{pg} \cdot \mathrm{mL}^{-1}$ and $343.6 \pm 125.3 \mathrm{pg} \cdot \mathrm{mL}^{-1}$, respectively (table 1 ). The hHGF level in the control group was $339.5 \pm 61.8 \mathrm{pg} \cdot \mathrm{mL}^{-1}$.

The hHGF levels in the LR group significantly increased up to $433.6 \pm 128.1 \mathrm{pg} \cdot \mathrm{mL}^{-1} \quad(\mathrm{p}=0.003) \quad$ and $430.8 \pm 128.2 \mathrm{pg} \cdot \mathrm{mL}^{-1}$ $(p=0.001)$ in POD 1 and 3 , respectively. However, the same levels in the nonLR group were $333.2 \pm 77.0 \mathrm{pg} \cdot \mathrm{mL}^{-1}(\mathrm{p}=0.796)$ and $311.9 \pm 73.0 \mathrm{pg} \cdot \mathrm{mL}^{-1}(\mathrm{p}=0.490)$, respectively. The hHGF levels of POD $1(p=0.049)$ and POD $3(p=0.029)$ showed a significant difference between the groups. The hHGF levels of POD 14 decreased back to pre-operative levels in both groups. POD 14 levels were $328.1 \pm 81.6 \mathrm{pg} \cdot \mathrm{mL}^{-1} \quad(p=0.694)$ and $340.3 \pm 72.4 \mathrm{pg} \cdot \mathrm{mL}^{-1}(\mathrm{p}=0.931)$ in the $\mathrm{LR}$ group and nonLR group, respectively.

The hHGF levels in the malignant and benign groups were $344.4 \cdot 66.7 \mathrm{pg} \cdot \mathrm{mL}^{-1}$ and $338.5 \pm 109.0 \mathrm{pg} \cdot \mathrm{mL}^{-1}$, respectively, and did not show a statistical significance $(p=0.409)$. No significant difference was found between the control and malignant groups $(p=0.345)$, or the control and benign groups $(\mathrm{p}=0.152)$.

\section{DISCUSSION}

Liver regeneration after loss of hepatic tissue is a fundamental parameter of liver response to injury. Hepatocytes have a great replicative capacity and are capable of repopulating the liver. The liver can precisely regulate its growth as well as its mass. Surgical resection of hepatic lobes or hepatocyte loss resulting from viral or chemical injury triggers hepatocyte replication, while enlarged liver mass is corrected by apoptosis [11]. If $70 \%$ of a rat liver is removed surgically the liver will grow back to its original mass in 2 weeks. HGF has been shown to play the major role in the regeneration process of the liver. A similar

\begin{tabular}{|c|c|c|c|c|}
\hline \multirow[t]{2}{*}{ TABLE 1} & \multicolumn{4}{|c|}{$\begin{array}{l}\text { Human hepatocyte growth factor levels in the } \\
\text { lung resection (LR), the nonLR and control } \\
\text { groups }\end{array}$} \\
\hline & Pre-operative & POD 1 & POD 3 & POD 14 \\
\hline LR group & $333.2 \pm 72.9$ & $433.6 \pm 128.1^{\#}$ & $430.8 \pm 128.2^{\text {***}}$ & $328.1 \pm 81.6^{\circ}$ \\
\hline NonLR group & $343.6 \pm 125.3$ & $333.2 \pm 77.0^{+}$ & $311.9 \pm 73.0^{5}$ & $340.3 \pm 72.4^{f}$ \\
\hline Control & $339.5 \pm 61.8$ & & & \\
\hline$p$-value & 0.879 & 0.049 & 0.029 & 0.670 \\
\hline
\end{tabular}


compensatory growth occurs in the lung following pulmonary resections to compensate for the loss of volume and/or gasexchanging function [7], and HGF appears as the prime growth factor responsible for the compensatory growth of the lung [8].

HGF is a multifunctional growth factor which has hepatotrophic and nephrotrophic functions for the regeneration of liver and kidney as well as for the lung. It was first purified to homogeneity from rat platelets and was a heterodimer composed of $69 \mathrm{kD} \alpha$-subunits and $34 \mathrm{kD} \beta$-subunits [12]. HGF is widely distributed, and HGF mRNA is found in relatively high concentrations in the rat lung as well as in the liver $[13,14]$. The major sources of HGF in the lung are mesenchymal cells, such as macrophages, fibroblasts, and endothelial cells, but not alveolar epithelial cells [14]. HGF has also been isolated from medium conditioned by human lung fibroblasts, and the receptor for HGF is the heterodimeric cmet proto-oncogene product, which has been found in the rat lung [6]. Human HGF stimulates DNA synthesis in airway epithelial cells and alveolar type II cells that contribute to regenerating the alveolar structure as progenitor cells $[8,15]$.

Although it was not feasible to prove by histological and morphometric analysis of the remaining lung in the human model, the present data demonstrated that patients who underwent pulmonary resections showed a significant increase in the serum levels of hHGF compared with patients who underwent nonLR thoracic surgical procedures. Similarly, SUGAHARA et al. [6] found three- to five-fold increases at 1-3 days in the serum hHGF levels of eight patients who underwent pulmonary resections, compared with five patients who underwent mastectomy. Likewise, a previous study investigating the serum and body fluid levels of hHGF and interleukin (IL)-6 among patients that underwent hepatectomy, thoracic surgery and abdominal surgery showed that the increase in the serum levels of hHGF was greatest in the hepatectomy group, followed by the thoracic surgery and abdominal surgery groups. The serum level of IL-6, an indicator for the severity of surgical injury, was greatest in the thoracic surgery group. The authors also found that the levels of hHGF and IL-6 in pleural fluids were significantly greater in the thoracic surgery group compared with the peritoneal fluids of the hepatectomy and abdominal surgery groups. It was suggested that thoracic surgery had caused more severe surgical injury than had occurred during abdominal surgery [10]. This finding implies that the necessity for the increase of hHGF is very likely to be higher in patients undergoing thoracic surgery. Conversely, NAYERI et al. [16] found low levels of hHGF in patients who died following pneumonia compared with survivors. They concluded that hHGF secreted from the injured lung was essential for the regeneration of the lung and that the nonsurvivors were unable to increase their hHGF levels. The above findings prove that the lung is one of the major sources of HGF. Similarly, the present results displayed increased levels of hHGF following LR compared with nonLR procedures, which presumably were derived from the lung tissue.

The intravenous injection of human recombinant HGF into mice with acute lung injury, induced by the intratracheal infusion of HCL, stimulates DNA synthesis of airway epithelial cells to levels three-fold higher than those in mice with no HGF injections [15]. Similarly, neutralisation of endogenous HGF by an antibody in pneumonectomised mice suppresses the compensatory DNA synthesis in lung epithelial cells; whereas administration of recombinant HGF to pneumonectomised mice stimulates DNA synthesis in lung epithelial cells [8]. It has also been shown that simultaneous or delayed administration of HGF equally repressed the fibrotic changes in murine lung injury induced by bleomycine [17]. In a pulmonary ischaemia-reperfusion model, marked increase in the expression of HGF mRNA occurred and neutralisation of HGF enhanced the pulmonary injury and, thus, delayed tissue generation [18]. In addition, post-operative respiratory failure, requiring ventilatory support by positive-pressure mechanical ventilation, can injure the lung resulting in oedema, alveolar inflammation and so-called ventilator-induced lung injury. Administration of hHGF may be an aid in the management of such a ventilator-induced lung injury [19]. These data imply that HGF as a therapeutic factor deserves attention as it may prevent pulmonary fibrosis, decrease ischaemia-reperfusion injury in the settings of lung transplantation and accelerate compensatory growth of the remaining lung after pulmonary resection. The current authors think that further studies investigating the feasibility of major pulmonary resections, such as pneumonectomy by exogenous administration of recombinant HGF in respiratory compromised animal models, are warranted.

TAKIGAWA et al. [20] reported that serum hHGF levels increased in patients with small cell lung carcinoma, and this might not have been related to tumour burden. There were no patients with small cell lung carcinoma in the present study, however, there was no significant difference observed in hHGF levels between the patients with benign diseases and patients with nonsmall cell lung carcinoma $(p=0.409)$. There was no significant difference in hHGF levels between the control group and malignant group $(\mathrm{p}=0.345)$.

In conclusion, hepatocyte growth factor may play an important role as an intrinsic pulmotrophic factor for the regeneration and compensatory growth of the lung following pulmonary resections. Moreover, intravenous administration of recombinant single-chain hepatocyte growth factor may be attempted as either a preventative measure or to support the effect of hepatocyte growth factor following pulmonary resection.

\section{ACKNOWLEDGEMENTS}

The authors would like to thank A. Saray for critically reviewing the manuscript.

\section{REFERENCES}

1 Deslauriers J, Ferraro P. Late complications. In: Pearson FG, Cooper JD, eds. Thoracic Surgery. Philadelphia, Churchill Livingstone, 2002; pp. 189-207.

2 Shields TW. General features of pulmonary resections. In: Shields TW, Lo Cicero J, Ponn RB, eds. General Thoracic Surgery. Philadelphia, Lippincott Williams \& Wilkins, 2000; pp. 375-384.

3 Kaza AK, Kron IL, Kern JA, et al. Retinoic acid enhances lung growth after pneumonectomy. Ann Thorac Surg 2001; 71: $1645-1650$. 
4 Kaza AK, Kron IL, Long SM, et al. Epidermal growth factor receptor up-regulation is associated with lung growth after lobectomy. Ann Thorac Surg 2001; 72: 380-385.

5 Verghese GM, McCormick-Shannon K, Mason RJ, Matthay MA. Hepatocyte growth factor and keratinocyte growth factor in the pulmonary edema fluid of patients with acute lung injury. Am J Respir Crit Care Med 1998; 158: 386-394.

6 Sugahara K, Matsumoto M, Baba T, Nakamura T, Kawamoto T. Elevation of serum hepatocyte growth factor level in patients with pneumonectomy during perioperative period. Intensive Care Med 1998; 24: 434-437.

7 Mason RJ. Hepatocyte growth factor. The key to alveolar septation. Am J Respir Cell Mol Biol 2002; 26: 517-520.

8 Sakamaki Y, Matsumoto K, Mizuno S, Miyoshi S, Matsuda H, Nakamura T. Hepatocyte growth factor stimulates proliferation of respiratory epithelial cells during postpneumonectomy compensatory lung growth in mice. Am J Respir Cell Mol Biol 2002; 26: 525-533.

9 Hsia CC, Herazo LF, Fryder-Doffey F, Weibel ER. Compensatory lung growth occurs in adult dogs after right penumonectomy. J Clin Invest 1994; 94: 405-412.

10 Kimura F, Miyazaki M, Suwa T, et al. Correlation between human hepatocyte growth factor and interleukin-6 concentrations after surgery. Hepatogastroenterology 1999; 46: 1030-1035.

11 Fausto N. Liver regeneration. J Hepatol 2000; 32: 19-31.

12 Nakamura T, Nawa K, Ichihara A. Partial purification and characterization of hepatocyte growth factor from serum of hepatectomized rats. Biochem Biophys Res Commun 1984; 122: 1450-1459.
13 Mason RJ, Leslie CC, McCormick-Shannon $\mathrm{K}$, et al. Hepatocyte growth factor is a growth factor for rat alveolar type II cells. Am J Respir Cell Mol Biol 1994; 11: 561-567.

14 Yanagita K, Matsumoto K, Sekiguchi K, Ishibashi H, Nio Y, Nakamura T. Hepatocyte growth factor may act as a pulmotrophic factor on lung regeneration after acute lung injury. J Biol Chem 1993; 268: 21212-21217.

15 Ohmichi H, Matsumoto K, Nakamura T. In vivo mitogenic action of HGF on lung epithelial cells: pulmotrophic role in lung regeneration. Am J Physiol 1996; 270: 1031-1039.

16 Nayeri F, Nilsson I, Skude G, Brudin I, Soderstrom C. Hepatocyte growth factor (HGF) in patients with pneumonia: a comparison between survivors and non-survivors. Scand J Infect Dis 1998; 30: 405-409.

17 Yaekashiwa M, Nakayama S, Ohnuma K, et al. Simultaneous or delayed administration of hepatocyte growth factor equally represses the fibrotic changes in murine lung injury induced by bleomycine. A morphologic study. Am J Respir Crit Care Med 1997; 156: 1937-1944.

18 Yamada T, Hisanaga M, Nakajima Y, et al. Enhanced expression of hepatocyte growth factor by pulmonary ischemia-reperfusion injury in the rat. Am J Respir Crit Care Med 2000; 162: 707-715.

19 Yamamoto H, Teramoto H, Uetani K, Igawa K, Shimizu E. Stretch induces a growth factor in alveolar cells via protein kinase. Respir Physiol 2001; 127: 105-111.

20 Takigawa N, Segawa Y, Maeda Y, Takata I, Fujimoto N. Serum hepatocyte growth factor/scatter factor levels in small cell lung cancer patients. Lung Cancer 1997; 17: 211-218. 